\title{
Statistical Modelling Of Global Solar Radiation On Horizontal Surface Using Monthly Means Daily Sunshine Hours And Some Climatic Variables For Zamfara State, Nigeria
}

\author{
${ }^{1}$ Hamza, B and ${ }^{2}$ Abdulmuminu, I \\ ${ }^{1}$ Department of Physics, \\ Usmanu Danfodiyo University, \\ Sokoto, Nigeria. \\ ${ }^{2}$ Department of Physics \\ Federal University Gusau, \\ Zamfara, Nigeria.
}

\begin{abstract}
In this study, four empirical models on the basis of linear Angstrom- Prescotte model for predicting monthly mean daily global solar radiation on horizontal surface were developed, correlating solar radiation to climatic parameters of sunshine hours, temperature and relative humidity. The models were used to predict Global solar radiation, an average solar radiation of 16.9690 $\mathrm{Mjm}^{-\mathbf{2}}$ day $^{-1}$ and maximum and minimum of 19.2647 and $13.5222 \mathrm{C}^{0}$ were respectively predicted. For validation and the accuracy of the models, statistical coefficient of determination, $R^{2}$, mean percentage error, (MPE), mean bias error, (MBE), and root mean square error (RMSE) were used. The result showed that, model correlating solar radiation with Sunshine hours, temperature and relative humidity gives the best fit for the study location with $R^{2}=83.89 \%$, that was;

$\frac{H_{p}}{H_{o}}=0.491+0.188\left(\frac{n}{N}\right)+0.02\left(\frac{T_{\min }}{T_{\max }}\right)-0.341\left(\frac{R H}{100}\right)$
\end{abstract}

Keywords: Empirical Models, Global Solar Radiation, Climatic Parameters And Statistical Errors.

\subsection{INTRODUCTION}

Solar radiation is the radiant energy emitted by the sun from continuous nuclear fusion reaction that creates energy and travels through space to the earth surface in short-wave length [1].

Solar radiation comes in many forms such as visible light, radio waves, heat (infrared), x-rays, and ultraviolet rays. Measurements of solar radiation are higher on clear, sunny day and usually low on cloudy days. When the sun is down, or there are heavy clouds blocking the sun, solar radiation is measured at zero. Solar radiation provide the earth with free, clean and inexhaustible source of energy, which if harness and utilized effectively, is of great importance to the world's high energy demand especially at this time of rising fuel costs and environmental effects such as depletion of the ozone layer and greenhouse effect [2].

This global energy crisis experienced from 1970's to date has led to intensify efforts on solar energy utilization through design and construction of solar energy systems. The comprehensive design and performance evaluation of these solar energy systems, for any particular location requires the availability of high quality global and diffuses radiation data. The best radiation data are those obtained from experimental measurements of the global and diffuse radiation components at the location under study. But due to the high cost of establishing and maintaining solar radiation measurement stations, global solar radiation in Nigeria is 
measured at some stations while diffuse solar radiation is not observe experimentally in any meteorological station of the country [3]. Hence several models are being developed to calculate global solar radiation using various climatic parameters. This Paper is aimed to develop equations or models for calculating Solar Radiation for Zamfara state.

Generally three classes of models for estimating radiation are in existence [4] the first class is empirical where meteorological data are used with regression techniques, the second class is based on the solar constant by allowing for depletion due to absorption and scattering by atmospheric gases, dust particles and aerosols and clouds, and the third class is based on satellites measurements of solar energy scattered and reflected into space by earth-atmosphere system.

Angstrom, [5]. developed the earliest model used for estimating global solar radiation, in which sun shine duration data and clear sky radiation $\left(\mathrm{H}_{\mathrm{c}}\right)$ were used.

$\frac{H_{m}}{H_{c}}=a+b * \frac{n}{N}$

$H_{m}$ is the monthly mean global solar radiation measured on horizontal surface $\left(\mathrm{MJm}^{-2} \mathrm{day}^{-1}\right)$,

$n$ is the monthly mean daily bright sun shine hours measured in hours, and

$N$ is the maximum possible monthly mean daily sunshine in Hours, (that is, monthly average day length) while 'a and ' b'are empirical Constants.

But this model was modified to a more convenient form by Prescott [6]. replacing clear Sky radiation $H_{c}$ with extraterrestrial radiation $H_{o}$ so that equation (1) becomes Angstrom-Prescott regression equation [7] ; [8] given as

$\frac{H_{m}}{H_{0}}=a+b * \frac{n}{N}$

$$
\boldsymbol{K}_{T}=\frac{\boldsymbol{H}_{m}}{\boldsymbol{H}_{\mathrm{o}}}
$$

$K_{T}$ is the clearness index and $H_{o}$ is the extra-terrestrial solar radiation which is theoretical.

\subsection{MATERIALS AND METHOD}

The input data of measured monthly mean daily sunshine hours, solar radiation and maximum and minimum temperature, relative humidity, latitude and longitude angles of the location were collected from Nigerian Meteorological Agency (NIMET) Gusau, under the Nigerian Federal Ministry of Aviation. The data obtained covered a period of 10 years (2005-2014).

Other data of extra-terrestrial radiation, declination angle, Sun set angle, maximum possible Sunshine duration (length of the day) were theoretically calculated.

\subsection{Models used}

The models proposed are based on the linear relationship among meteorological variables.

$\frac{H_{m}}{H_{0}}=A_{1}-B_{1} \frac{n}{N}$

$\frac{H_{m}}{H_{0}}=A_{\mathbf{2}}-B_{\mathbf{2}} \frac{T_{\min }}{T_{\max }}$

$\frac{H_{m}}{H_{0}}=A_{3}-B_{3} \frac{R H}{100}$ 


$$
\frac{H_{m}}{H_{o}}=A_{4}+B_{4} \frac{n}{N}+C_{1} \frac{T_{\min }}{T_{\max }-D_{1} R H}
$$

where $H_{m}$ is the measured monthly mean daily global solar radiation, $H_{\circ}$ is the monthly mean daily extra-terrestrial radiation, $\mathrm{n}$ is the monthly mean daily hours of bright sunshine in hours, $\mathrm{N}$ is the monthly mean daily day length while $A, B C D$ are regression constants

$H_{0}=\frac{24 * 360}{\pi} I_{S C}\left[1-0.033 \operatorname{Cos} \frac{360 d}{365}\right] *\left[\operatorname{Cos} \theta \operatorname{Cos} \delta \operatorname{Sin} \sigma+\frac{\pi}{180} \sigma \operatorname{Sin} \theta \operatorname{Sin} \delta\right]$

whereIsc $=1367 \mathrm{Wm}^{-2}$ is the solar constant, $\theta$ is the latitude angle of the location ( $\theta=12.170$ ), $\delta$ is the declination angle while

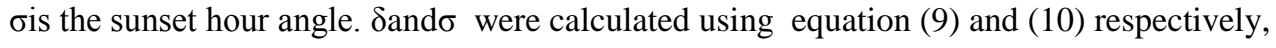

$\delta=23.34\left[360\left(\frac{284+d}{365}\right)\right]$

$\sigma=\cos ^{-1}[-\tan \theta \tan \delta]$

Where $d$ is the mean day of each month in a year, usually $15^{\text {th }}$ of each month, the day of the month on which the solar declination is calculated, [7] ; [8].

\subsection{Calculating regression constants.}

To determine the regression constant the first order linear regression equation was employed as given below [9].

$\mathrm{A}+\mathrm{B} x+\mathrm{Cy}+\mathrm{Dz}=K_{T}$

Where $\quad x=\frac{n}{N}, y=\frac{T_{\min }}{T_{\max }} \quad z=\frac{R H}{100} \quad$ and $\quad K_{T}=\frac{H_{m}}{H_{o}}$

It is an equation of least square line or first order regression. To perform the regression analysis of least square line, both sides of the Equation (11) have to be multiplied by $1, \mathrm{x}, \mathrm{y}$ and $z$ successively and summing both sides to obtain equations below [9]. (Adhikari, et al., 2013)

$$
\begin{aligned}
& t A+B \sum x+C \sum y+D \sum Z=\sum K_{T} \\
& t \sum_{x+B} \sum x^{2}+C \sum x y+D \sum x Z=\sum K_{T} x \\
& t \sum y+B \sum x y+C \sum y^{2}+D \sum y Z=\sum K_{T} y \\
& { }^{t} \sum{ }^{2}+B{ }^{B} \sum_{x Z}+C \sum y Z+D \sum Z^{2}=\sum K_{T} Z
\end{aligned}
$$

Where $t$ is the number of observations i.e number of months in a year. Solving equation (12) to equation (15) yields equation (16) and (17) For one variable models, Crammers rule, for $2 \times 2$ matrixes was used to obtain the regression constants 
When $x=\frac{n}{N}, y=\frac{T_{\min }}{T_{\max }} \quad z=\frac{R H}{100} \quad$ and $\quad K_{T}=\frac{H_{m}}{H_{o}}$

$\left[\begin{array}{cc}t & \sum x \\ \sum x & \sum x^{2}\end{array}\right]\left[\begin{array}{l}A_{1} \\ B_{2}\end{array}\right]=\left[\begin{array}{l}\sum K_{T} \\ \sum x K_{T}\end{array}\right]$

For the three variables model Crammers rule, for $4 \mathrm{x} 4$ matrixes was used to obtain the regression constants by putting the values of $\mathrm{x}, \mathrm{y}, \mathrm{z}$ and $K_{T}$ in equation (17) respectively.

When $x=\frac{n}{N}, y=\frac{T_{\min }}{T_{\max }} \quad z=\frac{R H}{100} \quad$ and $\quad K_{T}=\frac{H_{m}}{H_{o}}$

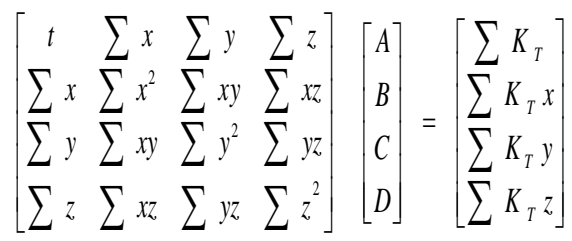

\subsection{Validation of the global solar radiation models (statistical analysis)}

The performance or accuracy of the proposed models was tested by calculating the coefficient of determination $R^{2}$, mean bias error $(M B E)$, root mean square error (RMSE) and mean percentage error (MPE). Coefficient of determination $R^{2}$ shows the linearity between the predicted and observed (measured) values. In regression, the $R^{2}$ coefficient of determination is a statistical measure of how well the regression line approximates the real data points, that is, goodness of fit of the regressor. $R^{2}=1$ if the fit is perfect and zero when the regressor has no explanatory power whatever, and can be obtained by using the relation below:

$$
R^{2}=\frac{\sum\left(H_{P . i}-H_{P . a}\right)\left(H_{m, i}-H_{m, a}\right)}{\sqrt{\left(Y \sum\left(H_{P . i}-H_{P . a}\right)\right) 2 Y Y \sum\left(H_{m, i}-H_{m, a}\right) 2 Y}}
$$

$H_{P}$, and $H_{m},{ }_{i}$ are the ith predicted and measured values while $H_{m},{ }_{a}$ and $H_{P},{ }_{a}$ are the average measured and predicted values of global solar radiation, and $N$ is the number of observations.

$M B E$ and $R M S E$ are also worked out to check the accuracy of relationships and measure. These are defined as

$$
\begin{aligned}
& M B E=\left[\sum\left(H_{P, i}-H_{m, i}\right) / N\right] \\
& R M S E=\left[\sum \frac{\left(H_{P . i}-H_{m, i}\right)^{2}}{N}\right]
\end{aligned}
$$

The mean percentage error is a measure of percentage deviation between the estimated and measured values or measure of accuracy of estimation computed by using the following relation 


$$
M P E=\sum\left[\frac{\left(\frac{H_{m, i}-H_{P, i}}{H_{m, i}}\right)}{N} X 100\right]
$$

$R S M E$ test provides information on the short-term performance whereas $M B E$ and $M P E$ test provide information on the long term performance. Positive MBE indicates underestimation whereas negative one the overestimation [10]. In general, low values of root mean square error (RMSE), mean bias $(M B E)$ and mean percentage error (MPE) are desirable [11].

\subsection{Calculated input variables}

Table 1: Calculated input variables

\begin{tabular}{|c|c|c|c|c|c|}
\hline Month & $\begin{array}{l}\quad \quad \mathrm{N} \\
\quad(\mathrm{Hrs}) \\
\text { Monthly } \\
\text { mean } \\
\text { Day } \\
\text { length }\end{array}$ & $\begin{array}{l}\qquad \frac{n}{N}{ }^{(H r s)} \\
\text { Monthly mean } \\
\text { daily Sunshine } \\
\text { fraction }\end{array}$ & $\begin{array}{l}\frac{T_{\min }}{T_{\max } \overline{I I}} \\
\text { Monthly mean } \\
\text { daily temperature } \\
\text { ratio }\end{array}$ & $\begin{array}{l}K_{T}=\frac{H_{m}}{H_{0}} \\
\text { Monthly mean } \\
\text { daily Clearness } \\
\text { index }\end{array}$ & $\begin{array}{l}\quad H_{\mathbf{0}} \\
\left(\mathrm{MJm}^{-\mathbf{z}} \text { day }^{-\mathbf{1}}\right) \\
\text { Monthly mean } \\
\text { daily extra- } \\
\text { terrestrial } \\
\text { Radiation }\end{array}$ \\
\hline Jan & 11.3733 & 0.4045 & 0.5139 & 0.5014 & 32.3676 \\
\hline Feb & 11.6133 & 0.4339 & 0.5603 & 0.5362 & 34.8206 \\
\hline Mar & 11.9333 & 0.4626 & 0.5946 & 0.5453 & 36.5458 \\
\hline Apr & 12.0200 & 0.5425 & 0.6565 & 0.5038 & 38.5479 \\
\hline May & 12.5600 & 0.5597 & 0.6834 & 0.4539 & 40.1180 \\
\hline Jun & 12.6933 & 0.5081 & 0.7036 & 0.3820 & 40.7565 \\
\hline July & 12.6235 & 0.5125 & 0.7125 & 0.3428 & 40.2862 \\
\hline Aug & 12.3835 & 0.4353 & 0.7393 & 0.3503 & 38.8557 \\
\hline Sep & 12.0550 & 0.4687 & 0.6949 & 0.4387 & 36.8849 \\
\hline Oct & 11.7170 & 0.4890 & 0.6305 & 0.4846 & 34.9948 \\
\hline Nov & 11.4371 & 0.4547 & 0.5093 & 0.5686 & 31.7646 \\
\hline Dec & 11.3038 & 0.4202 & 0.4874 & 0.5023 & 33.2483 \\
\hline$\Sigma$ & & 5.6917 & 7.4862 & 5.6099 & \\
\hline
\end{tabular}

By substituting sum of values of $x, y, z$ and $K_{T}$ (sum of relative sunshine hours, sum of temperature ratio, , sum of percentage relative humidity and sum of the clearness index respectively) from the table above in to equation (16) and (17), matrices were obtained. Solving the matrices by crammer's rule will give the desired regression constants.

From equation (16), three sets of regression constants were obtained as

$\left[\begin{array}{cc}12 & 5.69 \\ 5.69 & 2.73\end{array}\right]\left[\begin{array}{l}A_{1} \\ B_{1}\end{array}\right]=\left[\begin{array}{l}5.609 \\ 2.649\end{array}\right]^{A_{1}}=0.672 B_{1}=0.42$

$\left[\begin{array}{cc}12 & 74862 \\ 7.4862 & 4.7567\end{array}\right]\left[\begin{array}{l}A_{2} \\ B_{\mathbf{2}}\end{array}\right]_{=}\left[\begin{array}{l}5.6099 \\ 3.4401\end{array}\right]^{A_{2}}=0.9006 B_{\mathbf{2}}=-0.6939$ 
International Journal of Advances in Scientific Research and Engineering (ijasre), Vol 7 (5), May-2021

\section{$\left[\begin{array}{cc}12 & 4.48 \\ 4.48 . & 2.1947\end{array}\right]\left[\begin{array}{c}A_{3} \\ B_{3}\end{array}\right]=\left[\begin{array}{l}5.6099 \\ 1.9301\end{array}\right] \quad A_{\mathbf{a}}=0.5849 B_{\mathbf{a}}=-0.3145$,}

From equation (17) the regression constants obtained are:

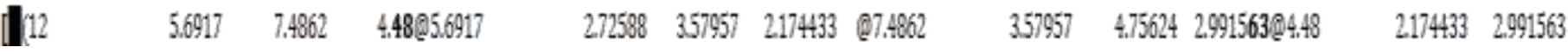

$\left[\begin{array}{c}\overline{\underline{D}} \\ 5.6099 \\ 2.638356 \\ 3.426409 \\ 1.921355\end{array}\right]$

$A_{4}=0.491 \quad B_{4}=0.188 \quad C_{1}=0.023 \quad D_{1}=-0.341$

\subsection{Proposed models}

Hence the modelled equations for Gusau are:

$\frac{H_{p}}{H_{0}}=0.671-0.429\left(\frac{n}{N}\right)$

$\frac{H_{p}}{H_{\circ}}=0.900-0.694\left(\frac{T_{\min }}{T_{\max } \mathrm{EI}}\right)$

$\frac{H_{p}}{H_{o}}=0.585-0.314\left(\frac{R H}{100}\right)$

$\frac{H_{p}}{H_{0}}=0.491+0.188\left(\frac{n}{N}\right)+0.02\left(\frac{T_{\min }}{T_{\max }}\right)-0.341\left(\frac{R H}{100}\right)$

\subsection{RESULTS}

Table 2: Measured and Predicted Monthly Mean Daily Global Solar Radiation

\begin{tabular}{|c|c|c|c|c|c|}
\hline \multirow[t]{2}{*}{ Month } & \multirow{2}{*}{$\begin{array}{l}H_{m} \\
\text { Measured } \\
\text { GSR } \\
M^{-\mathbf{2}} \text { day }^{-\mathbf{1}}\end{array}$} & Predicted $q$ & 1 solar radia & $m^{-2} d a y^{-1}$ & \multirow[b]{2}{*}{ Model 24} \\
\hline & & Model 21 & Model 22 & Mode 23 & \\
\hline Jan & 16.23 & 16.1013 & 17.6011 & 17.3026 & 16.9779 \\
\hline Feb & 18.67 & 16.8014 & 17.8138 & 19.1613 & 19.0892 \\
\hline Mar & 19.93 & 17.2684 & 17.8266 & 19.1914 & 19.2647 \\
\hline Apr & 19.42 & 16.8927 & 17.1474 & 18.1824 & 18.7209 \\
\hline May & 18.21 & 17.2848 & 17.0970 & 17.9139 & 18.5439 \\
\hline Jun & 15.57 & 18.4623 & 16.7978 & 16.9176 & 17.0719 \\
\hline July & 13.81 & 18.1733 & 16.3552 & 15.4557 & 15.5425 \\
\hline Aug & 13.61 & 14.3006 & 15.0519 & 14.0517 & 13.5222 \\
\hline Sep & 16.18 & 17.3667 & 15.4248 & 14.2483 & 14.0365 \\
\hline Oct & 16.96 & 16.1391 & 16.1983 & 16.2864 & 16.3825 \\
\hline Nov & 18.06 & 15.1169 & 17.3745 & 16.9803 & 16.9586 \\
\hline Dec & 16.70 & 16.3153 & 18.6914 & 17.7734 & 17.5175 \\
\hline
\end{tabular}


International Journal of Advances in Scientific Research and Engineering (ijasre), Vol 7 (5), May-2021

Table 3: values of the statistical error of the models (2005 to 2014)

\begin{tabular}{lllll}
\hline Model eqn. & $\mathrm{R}^{2}$ & MBE & MPE & RMSE \\
\hline 21 & 0.0773 & -0.2606 & 0.06801 & 2.1719 \\
22 & 0.6616 & 0.0025 & -0.7064 & 1.5570 \\
23 & 0.8251 & 0.0008 & -0.5501 & 1.1098 \\
24 & 0.8389 & 0.0019 & -0.3847 & 1.0744 \\
\hline
\end{tabular}

In table 3 above, the coefficients of determination $\left(R^{2}\right)$ of the four proposed models varies from 0.0773 to 0.8389 (which account for 7.73 to 83.89 per cent) close to unity indicating the good fitness of the models. Model equation 24 is the best with $R^{2}=83.89$ per cent, followed by modelled equation (23) and equation (22) with $R^{2}=82.51$ and 66.16 per cent then modelled equation (21) with $R^{2}=7.73$, modelled (21) has the least value with $R^{2}=7.73$ per cent. The result from equation 24,23 and 22 implies a very good match between the measured and predicted values of global solar radiation. But only modelled equation (21) has the lowest value of $R^{2}$ and higher value of $M P E$.

$M B E$ of three modelled equations are low and positive indicating slightly over estimation while only model (21) has the lowest and negative value indicating strong under estimation of the global solar radiation.

RMSE values are lowest for modelled equation (24), then equation (23), and equation (22) which indicated a very good accuracy measure of predicted global solar radiation. But for modelled equation (21), the RMSE is higher indicating less accuracy of the model. It was observed that the lower the $R M S E \%$, the more accurate the equation used. [12]. MPE values for these models are lowest and negative with the exception of model equation (21) having positive value.

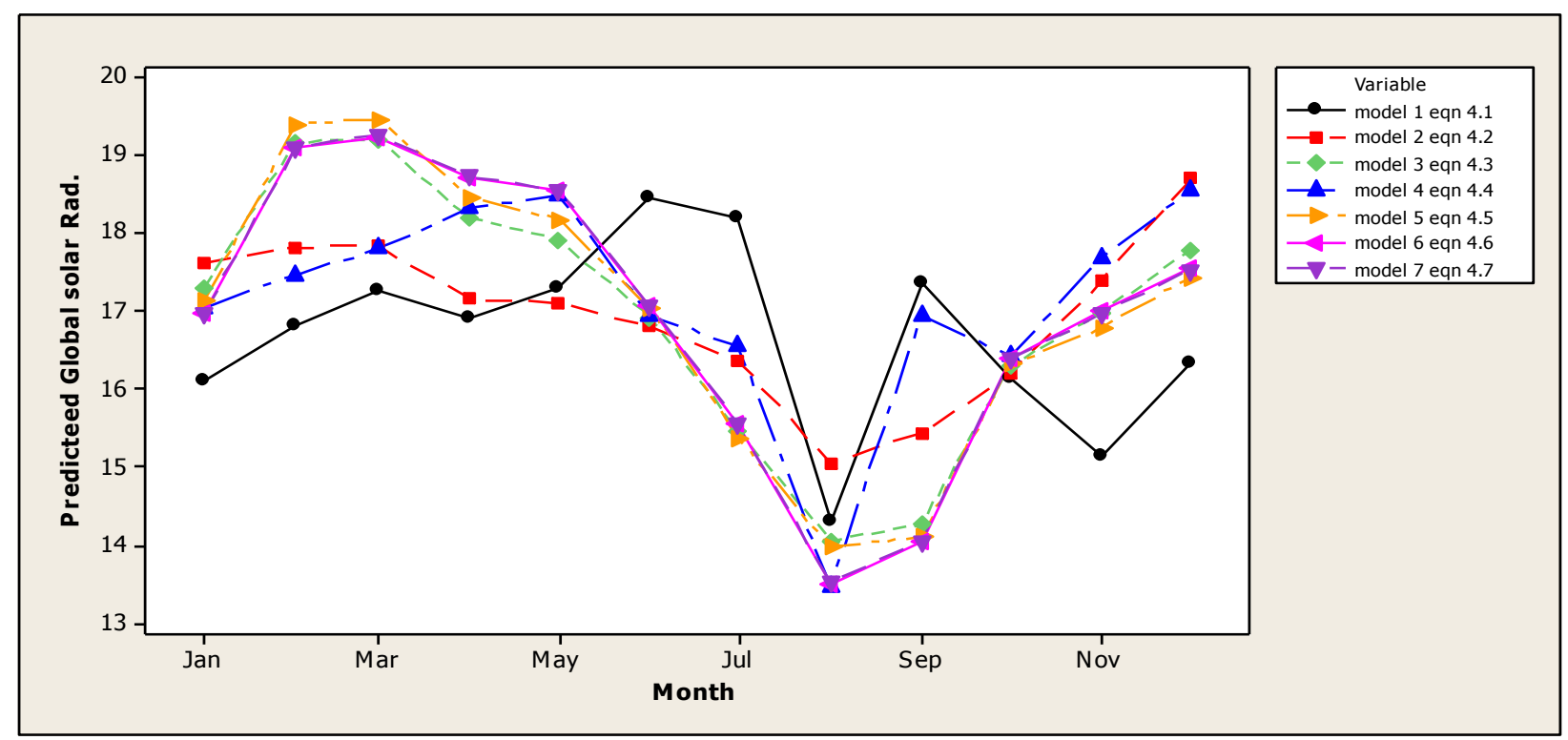

Figure 1: Monthly Variation of the Predicted Global Solar radiation 


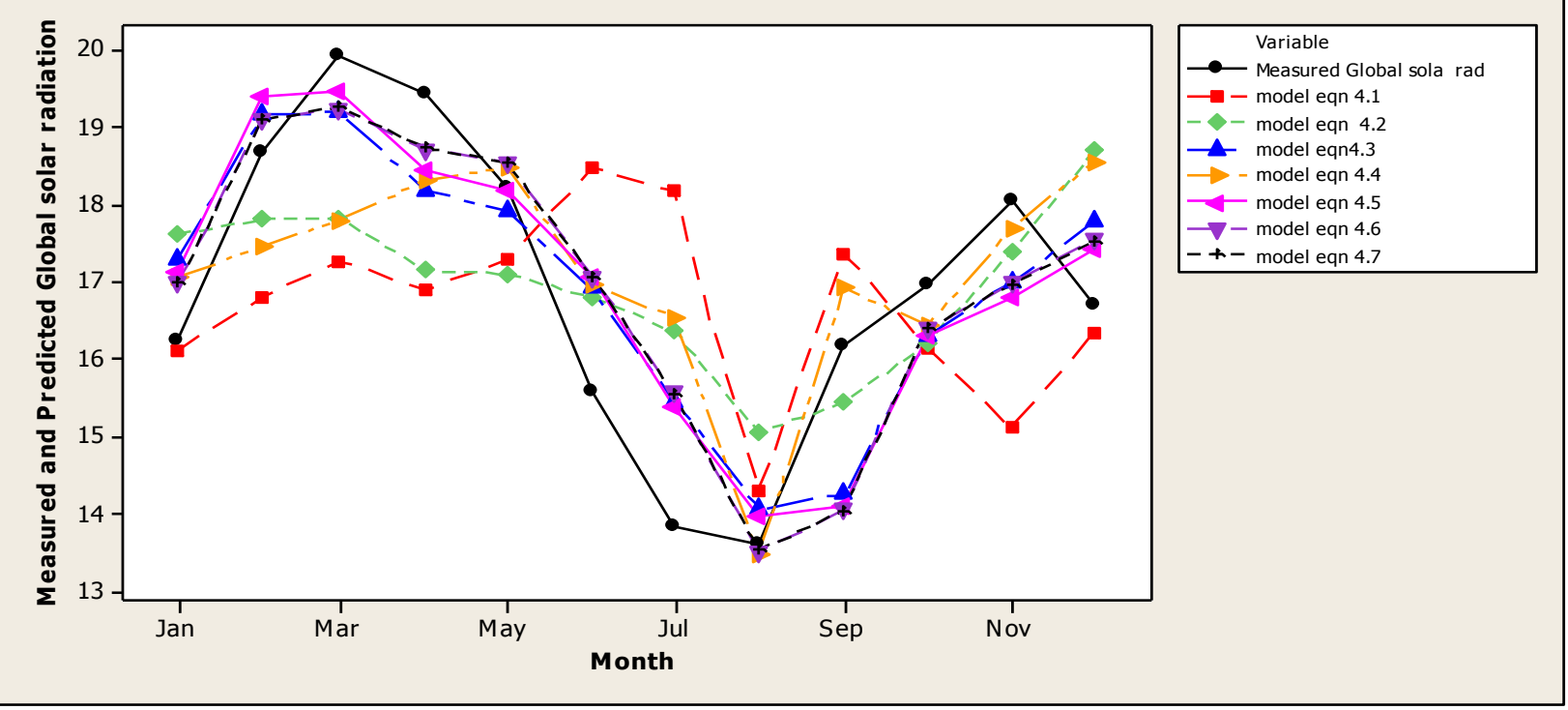

Figure 2: Comparison between Measured and predicted global solar radiation

\subsection{SUMMARY}

The main finding of the research may be summarized as follows: Four linear model equations for calculating monthly average daily global solar radiation on horizontal Surface from the sunshine ours and other meteorological variables on the basis of Angstrom- prescotte has been developed by calculating new sets of regression constants using crammer's rule. The models are expressed as a linear correlation between the global radiation and the sunshine duration, temperature ratio, and relative humidity. The performances of these models were investigated using statistical parameters, and it was found that global radiation predicted by three of these models are in good agreement with the observed or measured value, among the four models, model (24) is the best having $\mathrm{R}^{2}=83.89 \%$. The average value of the predicted global solar radiation for Gusau city in the period of study is (from model 24) is $16.9690 \mathrm{Mjm}^{-\mathbf{2}} \mathrm{day}^{\mathbf{- 1}}$ while the maximum and minimum are 19.2647 and $13.5222 \mathrm{Mjm}^{-\mathbf{2}} \mathrm{day}^{\mathbf{- 1}}$ respectively.

\subsection{CONCLUSION}

It was concluded that modelled equation (24) correlating solar radiation, sunshine duration, temperature ratio, and relative humidity is the best and can be used for predicting Global solar radiation for Gusau and other areas having similar climatic conditions.

\section{REFERENCE}

1. Adedoja, O. S., Ayantunji, B. G., Saleh, U. A., and Jatto, S.S. (2015). Diurnal and Seasonal Variation of Global solar Radiation: International Journal Of Engineering Science and Innovative Technology volume 4, 140- 144.

2. Gana, N. N., Jitendra, K. R. and Momoh, M. (2014). Estimation of Global and diffuse solar radiation for Kebbi, Northwestern Nigeria: International Journal of Scientific \& Engineering Research, Volume 5.

3. Akpootu, D. O. and Mustpah, W. (2015). Estimation of Diffuse Solar Radiation for Yola, Adamawa State, North- Eastern, Nigeria: International Research Journal of Engineering and Technology volume 2, 77-82.

4. Sambo, A. S. and Doyle, M. D. C. (1988). Correlation of Global Solar Radiation Components With Meteorological Data For Zaria: Nigerian Journal of Solar Energy Volume 7, PP 16-25.

5. Angstrom, A. (1924). Solar and Terrestrial Radiation: Q.J.R.Meteorological Soc. 50,12, pp 125. 
6. Prescott, J. A. (1940). Evaporation from water surface in relation to solar radiation, Transaction of the Royal Society of Australia, vol. 46, pp. 114-118.

7. Duffie, J. A. and Beckman, W. A. (2013).Solar engineering of thermal processes.FourthEdition Solar Energy A Laboratory University of Wisconsin-Madison: by John Willy\& Sons.

8. Tijjani, B. I. and Musa, A. O., (2011). Estimation of Global and Diffuse Solar Radiation From Monthly Average Daily sunshine Hours Data in Katsina, Nigeria.Bayero Journal of Physics and Mathematical Sciences Volume 4, No.1, pp11-19.

9. Adhikari, K. R., Bhattarai1, B. K., and Gurung, S. (2013). Estimation of Global Solar Radiation for Four Selected Sites in Nepal Using Sunshine Hours, Temperature and R.H: Journal of Power and Energy Engineering1,1-9 http://www.scirp.org/journal/jpee.

10. Karakoti, I., Kumar, D. P. and Singh, S. K. (2012). Monthly Mean daily Diffuse Radiation For India: Applied Energy volume 91, PP 412-425.

11. Ituen, E. E, Nsikan. U., Samuel, C. and Udo, E. G. (2012). Prediction of global solar radiation using relative humidity, maximum temperature and sunshine hours in Uyo, in the Niger Delta Region, Nigeria: Advances in Applied Science Research, Pelagia Research Library 3, (4).

12. Akpabio, L. E. and Etuk, S. E. (2003).Relationship between Global Solar Radiation and Sunshine Duration for Onne, Nigeria: Turkesh journal of physics Tubitak 161 to 167 retrieved on www.journals.tubitak.gov.tr.

Corresponding Author's Email Address: bshamza2024@gmail.com 